\title{
Intelectual and Creative Management Potential of Business Social and Economic Systems
}

\author{
Oleksii Hudzyns'kyi, Svitlana Sudomyr, Yuliia Hudzyns'ka, Maksym Zhukovs'kyi
}

\begin{abstract}
The system approach to the formation of the intellectual and creative management potential of business social and economic systems is substantiated in the article. The main meaningful components of the system approach as methodology of effective management of the sustainable development of business structures with social responsibility and innovative and creative potential have been emphasized. The system of factors considered while substantiating the criteria of the value of the efficient management of social and economic systems, on which the creation of models is based, has been formed. The main directions of the development of reaction types and behavior of social and economic systems have been substantiated. The key aspects of the system approach to the formation of management potential of social and economic systems have been discovered. The methods of determination of the synergy effect of realization of potential of social responsibility and intellectualization of the management of social and economic systems have been developed.
\end{abstract}

Key words. Development, management, effect, intellectual and creative potential, system, responsibility, models.

\section{INTRODUCTION}

Under the current conditions of accelerated system changes and transformations in the society there is an objective need to develop a new systematic methodological approach to the formation of intellectual and creative potential of business enterprise management as social and economic systems. The research of such problems is relevant. The scientific articles of O. Hudzyns'kyi [1], T.

Hurenko [1], T. Lunkina [5], P. Lyndner [6], B. Litovchenko [7], O. Prodius [8], O. Psdval'na [9], M. Kuzubova [3], Carol Yeh-Yun Lin [4], S. Sudomyr [1], M. Soprykina [2], P. Tsybul'kova [10] are partly devoted to the current issues in which they give their own views.

\section{METHODOLOGY}

During the research the method of system approach was used. It covers:

- content and semantic components of effective

Revised Version Manuscript Received on October 15, 2019.

Oleksii Hudzyns'kyi, department of management named after prof. Yi. S. Zavads'kyi, Faculty of Agricultural Management, National University of Life and Environmental Sciences of Ukraine, Kyiv, Ukraine. (Email: lunareclipse@ukr.net)

Svitlana Sudomyr, department of the economy of an enterprise SS NULES of Ukraine «Berezhany agro technical institute», Berezhany, Ukraine. (Email: sudomyr_s@ukr.net)

Yuliia Hudzyns'ka, department of management named after prof. Yi. S. Zavads'kyi, Faculty of Agricultural Management, National University of Life and Environmental Sciences of Ukraine, Kyiv, Ukraine. (Email: lunareclipse@ukr.net)

Maksym Zhukovs'kyi, department of epizootology and organization of veterinary business, Faculty of Veterinary Medicine, National University of Life and Environmental Sciences of Ukraine, Kyiv, Ukraine. (Email: nfvm@ukr.net) management of sustainable development of business structures with social responsibility and intuitive and creative potential;

- the system of factors that underlie the development of semantic models;

- priority goal setting, purposeful programs of action, value orientations;

- synergy principles of evaluation of social and economic systems with prioritized value orientation, intellectual and creative potential of management and social responsibility.

Methodology of mathematical models formation which covers:

- main components of system models in twenty directions of social and economic systems development;

- main aspects of the formation of potential with social responsibility;

- mathematical - in the development of methods of synergy effect determination and evaluation of social responsibility potential with the system of indicators according to the substantiated criteria;

- sociological - in the study of sustainable development of social and economic systems according to the types of their development and behavior.

\section{RESULT DESCRIPTION}

Under the current conditions of the dynamically changing market environment with an advanced system of organization and economic interactions with integrated subjects of production and functional support there is an objective need to develop a new system approach to the formation of an effective mechanism of management of sustainable development of business social and economic systems with the priority of value orientation, intellectual and creative management potential and social responsibility on the synergy basis.

The new system approach is based on (the main components):

- developed system thinking about formation of social and economic entities as system entities in their dynamically developing aspects and in the organically balanced unity of their components;

- system reinterpretation of scientific social and economic categories according to the direction of development and transformation;

- possible types of behavior of business organization social and economic systems;

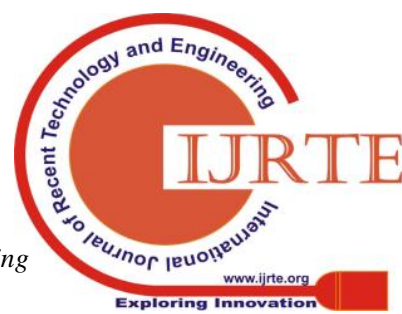


- value orientated views such as: priority target units: the main criteria of evaluation of business social and economic systems activity and the effectiveness of management systems;

- types of management by the directions of the activity

- synergy component as the main system requirement in substantiation of the integrated criterion of evaluation of the effectiveness of business social and economic systems and their management;

- information technologies of management process in the system of accounting and analytical support of social and economic business entities management;

- system knowledge of subjects of business social and economic entities management;

- management potential as the system integrity;

- innovative component of business social and economic systems as the main basis of intellectual and creative potential;

- intellectualization of the system of social and economic relations, filling with new content of intellectual potential of the subjects of managerial activity;

- civilized system of social responsibility and control.

The components of the system approach which have been put into the basis of substantiation of the system of indicators (evaluation criteria in the development of the efficient systems of management of social and economic systems) have been named.

At the same time we note that our proposed logic of the scientific approach requires the revision of the existing system of training specialists both in management and specialists in the design of business social and economic systems as system integrations with dynamically developing creative and innovative potential and intellectual one in the context of intellectualization. The methodological principles of such approach are partly developed by the authors of the article on practice.

This approach underlies the formation of information and mathematical models. Such position is dominant in the design of social and economic systems and management as an integrity system.

In social and economic systems, the main system-forming element of mathematical, cybernetic and other models there is the semantic (sense approach), and more detailed semantic models, which are built on goal setting and purposeful programs of action.

The latter ones are based on value orientations, which are the fundamental basis for the choice of organization models by the types of their development and behavior. All other models are the means and mechanisms of realization of the aims of semantic models, purpose-oriented views which cover the main directions of the development of social and economic systems. They are substantiated by us and are distinguished by certain features which are described in details in the monograph by O. D. Hudzyns'kyi, S. M. Sudomyr, T. O. Gurenko [1].

Mathematical and cybernetic models as the carriers of information are the mechanism connecting element between the semantic models of goal settings and technological means of informational display of meaningful purpose programs of dynamic and strategic development of social and economic and types of business social and economic systems behavior;

systems. Only with this approach it is possible to ensure the optimal balance of all components of the system and purposeful and functional support of the components of the system integrity of the synergy system development direction.

With this approach, a new essence and purposeful orientation of mathematical, cybernetic direction is being developed. At the same time we attach great importance to the philosophical approach to the formation of such systems in their organic unity and the interaction of value orientations, goal settings, organization types of behavior, organization culture, organization processes, organization climate, social responsibility.

In this aspect, on our point of view, we should approach to the development of theoretical and methodological regulations of the formation of social and economic systems and management as system integrity of the synergy direction. Therefore, we support the position of the scientists who propose to develop the logic of action according to the scheme "System - component of a system", but not vice versa [1]-[4], [10]. In this respect all the components of the system integrity have to be studied in-depth in relation to the maternal basis which is the "system" and its system properties.

Our research confirms the high effectiveness of such approach which covers all the directions of the development and types of reaction and behavior of social and economic systems in the context of: value-oriented, creative, innovative, incremental, strategic, competitive, anti-crisis, social, environmental, organizational, economic, activation, technical and technological, biological, managerial, intellectual, system-oriented, information, social responsibility, etc. directions of the development.

Such schematic interrelation is given in fig. 1 .

The mathematical model from the methodological point of view in our interpretation acts as the main system-connecting component (subsystem) between the semantic model in the context of all components of the purpose and function providing direction, which is the basis for the formation of effective management system of information support of business social and economic management systems and to provide their successful functioning with sufficiently high complex-directed synergy effect. However, we emphasize that system synergy effect in managing the activity of enterprises as social and economic systems can be provided only in the context of changes in value orientations, ethical components in hierarchical systems, substantiated models of organizations as integrities built on the unity of interests in optimal balanced system of social inequality. Substantiated system of accounting and analytical support of management of the activity of organizations which we have developed in the context of the proposed approach to the formation of models of implementation of social and economic programs of business structures with different types of their reaction and behavior in the process of dynamic development and the levels of social responsibility potential has to facilitate the mentioned above.

Published By:
\& Sciences Publication 


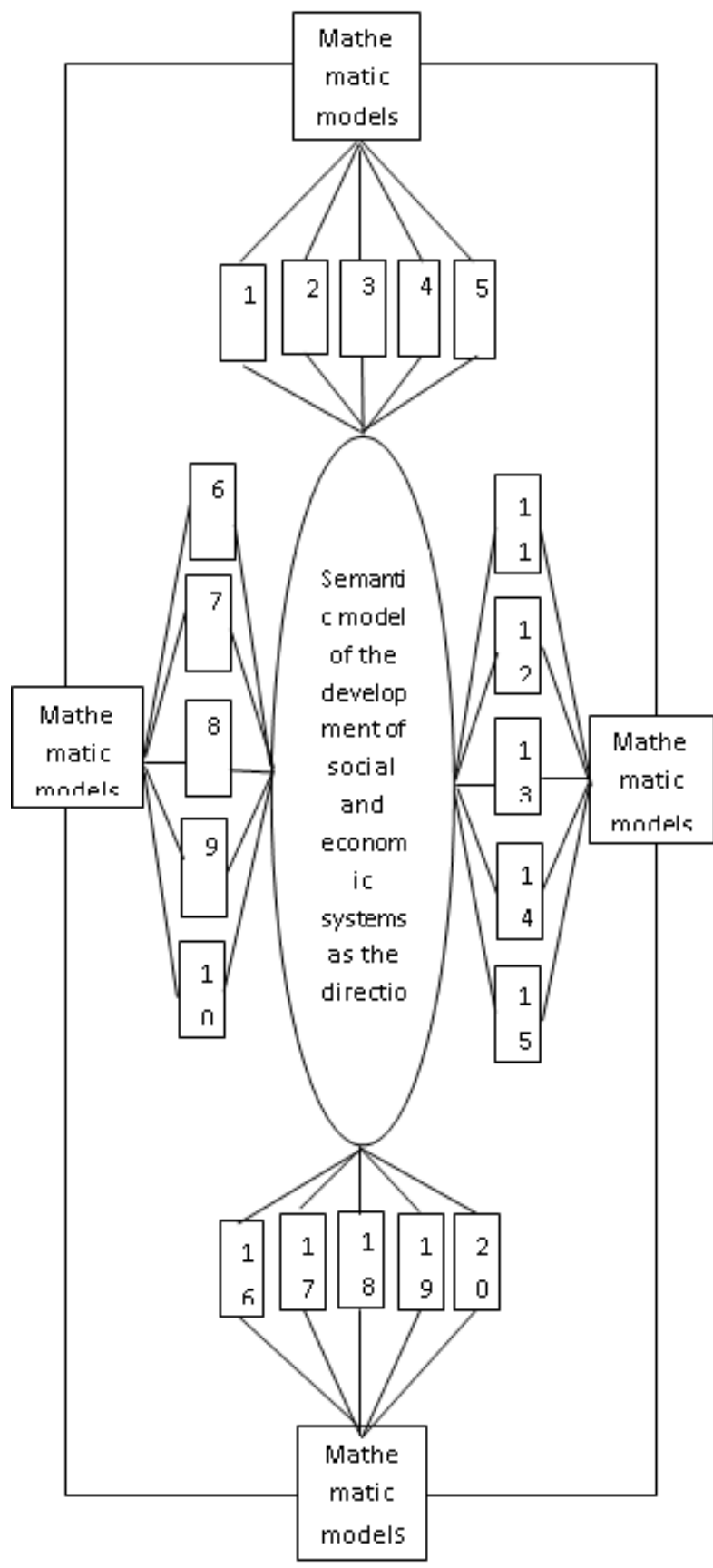

Fig. 1. Components of semantic approach to the formation of mathematical models

Note:

1-value-oriented;
- - creative;
3 -innovative;
4- incremental;
5 - strategic;
6-competitive;
7 - anti-crisis;
8- social;
9-environmental;
10-organizational;

11 - economic;

12 - activation;

13 - technical and technological;

14 - biological;

15 - managerial;

16 - intellectual;

17 - system-oriented;

18 - information;

19 - social responsibility;

20 - other directions of the development
The potential of social responsibility according to its content, structure, qualitative and quantitative parameters, purposes and other criteria of evaluation of the responsibility of an entity and management is ambiguous [2], [5]. There are also ambiguous models of social responsibility of strategic, local and operational direction, as well as fundamental strategies of social responsibility of the management subjects that will determine the specificity of formation of the intellectual potential of business social and economic systems management [8]-[9].

The completeness and meaningful filling of the potential of social responsibility depends, to a great extent, on the essential principles of understanding the concept of "social responsibility". Our interpretation of the concept of "social responsibility" of a subject of management of social and economic systems is considered as system responsibility to the society as a social and economic system integrity by the subjects of demand (consumers), contact audiences, subjects of functional control and responsibility and companies' employees according to:

- maintenance, retention and provision of sustainable development of ecological, social, economic environment in their organic unity as the fundamental basis of existence and vital activity of the humanity;

- maintenance and development of values, standard, generally accepted norms of behavior;

- maintenance and development of the organization culture, organization behavior, organization interaction, social climate as the fundamental basis of communication connections and power relations;

- support and development of the system of relations of power-ownership, subject-subject, subject-object, etc. in the system of interests of internal and external direction;

- discharge of obligations to the interest subjects, etc.

The proposed system approach which is the basis for highlighting the main aspects of the formation of the potential of social responsibility as the component of the intellectual potential of social and economic systems management (Fig. 2).

In the context of the proposed system approach the method of determination of the synergy effect according to the level of the development and system balance of the components of the potential of social responsibility and intellectual management of social and economic systems has been developed. It is proposed to determine the synergy effect according to a formula that covers the evaluation criteria according to the components of social responsibility distinguished by us (Fig. 3) according to the main blocks of social responsibility and the subjects of interaction. 


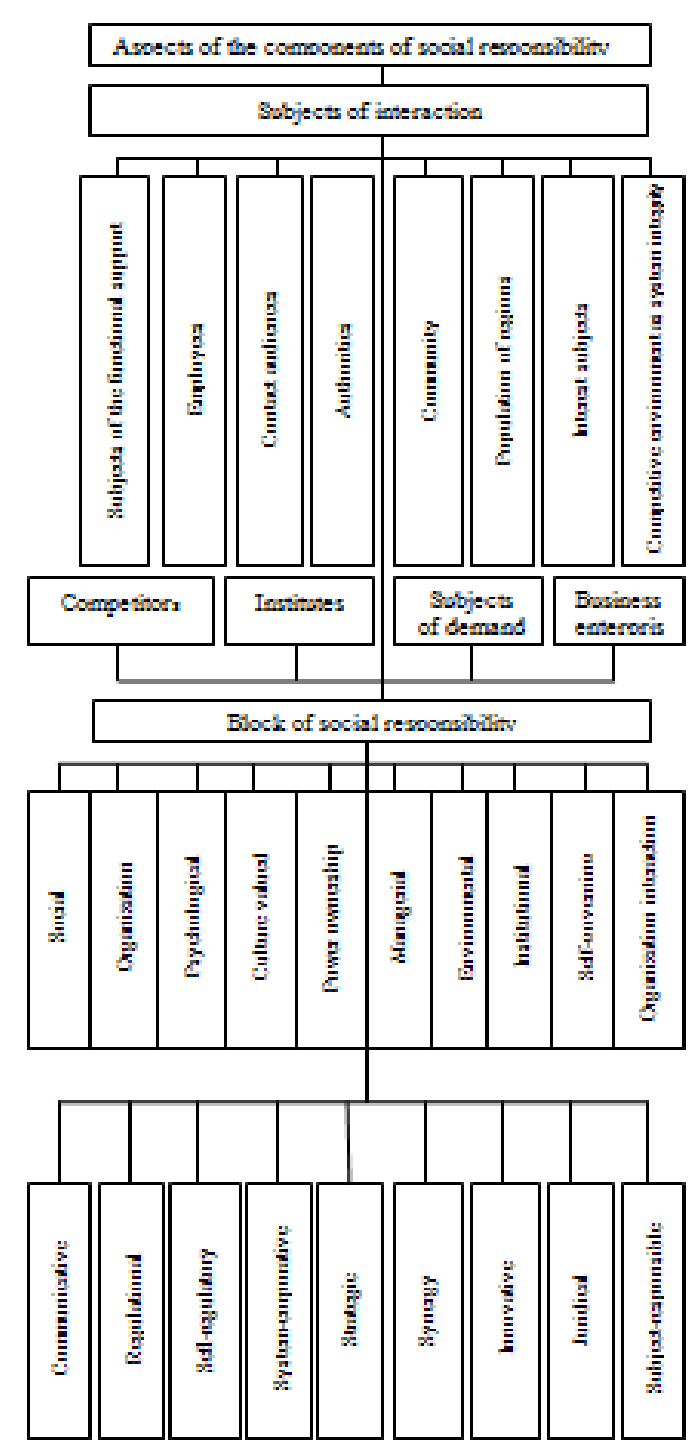

Fig. 2. The key aspects of the methodology of formation of the potential of social responsibility as the component of intellectual potential of social and economic systems management

The synergy effect of simultaneous implementation of all kinds of potential possibilities in their organic unity as systemic integrity will look like (formula (1)):

$$
C_{e \phi}=\sum_{e \phi c c} \times k_{n d}-\left(\sum_{e \phi 1}+\ldots+\sum_{e \phi 19}\right)+\sum_{e \phi c c} \times k_{n d}-\left(\sum_{e \phi 1}+\ldots+\sum_{e \phi 12}\right)
$$

where $C_{e \phi}$ - the synergy effect of the simultaneous system balance of the components of the potential of social responsibility and the intellectual management of social and economic systems; $\sum_{\text {eфç }}$ - sum of effects of simultaneous implementation of the components of social responsibility blocks; $\sum_{e \phi 1, \ldots . .} \sum_{e \phi 19}$ - sum of effects of implementation (social, psychological, organizational, culture-valued, power-ownership, managerial, environmental, institutional, self-governing, organization interactive, juridical, system-corporative, innovative, synergy, strategic, self-regulatory, subject responsible, regulatory, communicative); $k_{n \partial}$ - coefficient of coordination of action. $\sum_{\text {eqcs }}-$ sum of the effects of simultaneous implementation of subjects of interactions; $\sum_{e \phi 1, \ldots,} \sum_{e \phi 12}$ - sum of the effects of implementation (subjects of the functional support, contact audiences, business organizations, subjects of demand, institutes, interest subjects, competitive environment as system integrity, population of regions, communities, authorities, employees).

The developed method of synergy effect evaluation covers the groups of the main factors of success in the activity of social and economic systems and in the management system and is suitable for evaluation of the intellectualization process according to eight criteria (intellectual and innovative, activating, virtualization, knowledge, globalization, synergy, intellectual saturation, information) (Fig. 3).

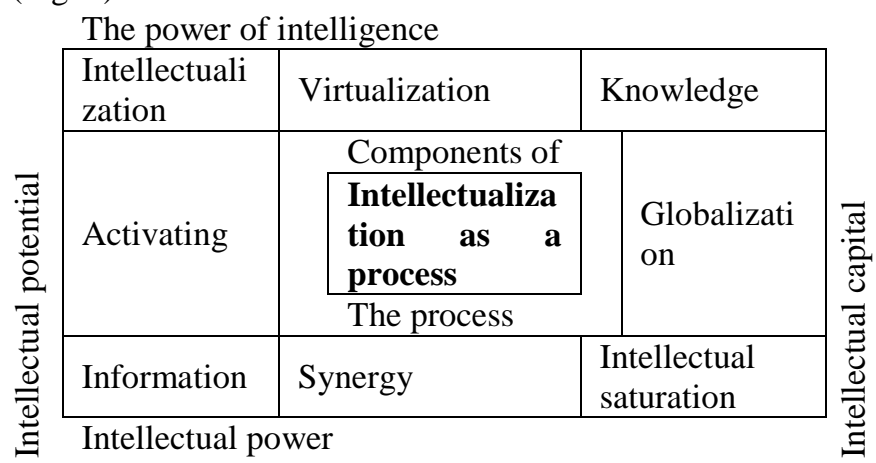

Fig. 3. Intellectualization as a process

In general, our substantial methodological approach to the formation of intellectual and creative potential of business social and economic entities management is systematic and can be used in efficient economy by determining the degree of competitiveness of management effectiveness at different levels: state, regional, economic structures, sectoral, functional and supportive, commodity.

\section{CONCLUSION}

Consideration of the intellectual and creative potential of the business social and economic entities management in the system synergy aspect is objectively necessary and is the fundamental basis of the methodology of the formation of an effective management system of the dynamically sustainable development of economic, functional and supportive structures. In the context of the proposed methodology it is established:

- systematization of the main components of the developed methodology of formation of intellectual and creative potential of management on the requirements of system approach will help to increase the effectiveness of management of specialists training both in management and specialists in the design of social and economic systems;

- the formation of semantic models based on goal settings, purposeful program actions, value orientations should be the fundamentals when choosing organization models according to the types of their development and behavior; 
- the essential concept of social responsibility, which underlies the determination of the main aspects of the methodology and the formation of the potential of "social responsibility" as the components of intellectual potential has been clarified;

- development of methodology of determination of the synergy effect and the social responsibility potential evaluation by the substantiated criteria of the system of indicators;

- the high efficiency of the proposed methodological approach to provide the sustainable development of social and economic systems according to the types of their development and behavior (in 12 directions) is confirmed by the research.

\section{REFERENCES}

1. O. Hudzyns'kyi, S. Sudomyr, T. Hurenko. Theoretical and methodological principles of the efficient management of enterprises development: [Monograph]. K.: TsP «Comprynt», 2017. $404 \mathrm{p}$.

2. M. Soprykina, O. Liashenko, M. Saensus, H. Mis'ko. Corporate social responsibility: models and management practice: textbook K.: Plc «Pharbovanyi lyst», 2011. 480 p.

3. M. Kuzubov, O. Edynak, N. Ovander/ Modeling of economic and ecological and economical processes: [monograph]. K.: KSU, 2010, $170 \mathrm{p}$

4. C. Yeh-Yun Lin, Leif Edvinsson National Intellectual Capital: A Comparison of 40 Countries. - Springer Science \& Business Media, 2010. - 392 p. 22. E

5. T. Lynkina Social responsibility of the entities of agrarian sector of the economy of Ukraine: [monograph]. Mykolaiv. 2018. $632 \mathrm{p}$.

6. P. Lyndner. Creative industries: from theoretical models to real projects [online resource]. access : http://www.hse.ru.

7. B. Litovchenko. Creative school of management for creative economy: challenge of time or illusion. Economic discourse: intern. compil. scient. w. 2015. Ed. 4. pp. 5-10.

8. O. Prodius. Creative management as guaranty of modern efficient management. Economy: time reality. 2012. № 3-4 (4-5). pp. 67-72.

9. O. Pidval'na. Manager of new generation / O. H. Pidval'na, T. Ye. Panasiuk // house Education and Science s.r.o. IČO : 27156 877 Frýdlanská 15/1314, Praha 8 MS v Praze , oddíl C,vložka 100614.

10. P. Tsybul'kov, V. Chobotariov, V. Zinov, Suini Yu. Management of intellectual property: [monograph]. K.: «KIC». 2005. $448 \mathrm{p}$.

\section{AUTHORS PROFILE}

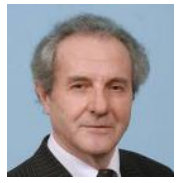

Professor O. Hudzyns'kyi is the prominent and famous scientist in management. His scientific activity is aimed at the development of theoretical and methodological foundations and practical recommendations for the improvement of the management system under the current conditions of institutional and structural transformations of the economy of Ukraine. They cover issues of: anti-crisis management, formation of competitive potential, innovative and sustainable development of social and economic systems, quality management of business structures, management of education of Ukraine. O. Hudzyns'kyi is the main developer of a comprehensive quality management training system of economic experts and co-author of the development of educational and professional programs and educational and qualification characteristics in the field of «Management». Professor Hudzyns'kyi is the author of more than 250 scientific papers in management issues, including 19 monographs, manuals and textbooks. He has prepared 39 candidates of economic sciences and 6 doctors of economics. OrcID: 0000-0001-6494-851X

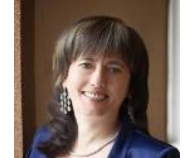

S. Sudomyr is a well-known scientist in the field of management. Her scientific activity is aimed at the development of theoretical and methodological foundations and scientific and practical recommendations for the formation of effective management system of the development of enterprises of strategic and competitive orientation on the basis of organic unity of the constituents as the foundation for providing their successful functioning under the conditions of dynamically changing competitive environment. Sudomyr S. M. is the author of more than 100 scientific papers in management issues, among which there are 15 monographs, manuals and textbooks. OrcID: 0000-0002-2574-1724

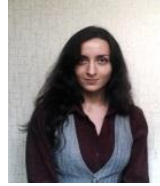

Yu. Hudzinska. is a young scientist in the field of management. Her scientific activity is aimed at the development of theoretical, methodological and practical recommendations for the strategic development management of enterprises and formation of a system ensuring their sustainable competitiveness in a highly competitive globalized market. Hudzinska Yu. S. is the author of more than 30 scientific papers in current management issues. OrcID: 0000-0002-6850-4059

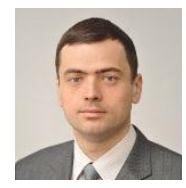

M. Zhukovs'kyi is a young scientist in management issues. His research is aimed at the development of an effective system of management of the agricultural enterprises competitiveness based on a process approach and a system of competitive advantages to provide the agricultural enterprises competitiveness in their dynamic and strategic development. Also the scientist's area of interest includes management issues in veterinary medicine. Zhukovsky M. O. is the author of more than 35 scientific papers in management issues including two monographs and a manual. OrcID: 0000-0002-6158-800X 